Cukurova Üniversitesi Mühendislik Mimarlık Fakültesi Dergisi, 33(2), ss. 73-82, Haziran 2018

Çukurova University Journal of the Faculty of Engineering and Architecture, 33(2), pp. 73-82, June 2018

\title{
Inconel 625-AISI 304L Malzeme Çiftinin Yüksek Nikelli İlave Metal ile Birleştirilmesi: Mikroyapısal ve Mekanik Özellikler
}

\author{
Mustafa TÜMER ${ }^{* 1}$ \\ ${ }^{1}$ Kocaeli Üniversitesi, Uzunçiftlik Nuh Çimento Meslek Yüksekokulu, Kaynak Teknolojisi \\ Programi, Kocaeli
}

Geliş tarihi: 17.01 .2018

Kabul tarihi: 29.06 .2018

$\ddot{\mathbf{O} z}$

Inconel 625 nikel esaslı süper alaşım ile AISI 304 L ostenitik paslanmaz çelik farklı cins malzeme çifti, TIG (gas tungsten arc welding) yöntemi ile ErNiCr3 ilave metali kullanılarak birleştirilmiştir. Birbirinden değişik fiziksel ve kimyasal özelliklere sahip farklı cins malzeme çifti yüksek nikel içeriğine sahip ilave metalle birleştirilmiş ve bağlantının kaynak metali (KM) mikroyapı, sertlik ve tokluk özelikleri incelenmiştir. Kaynak metalinde ve ergime sınırında (ES) meydana gelen mikroyapısal dönüşümler ve intermetalik fazlar karakterize edilmiştir. Ana malzemelerin ve ilave metalin içerdiği elementlerin oranlarına bağlı olarak meydana gelen mikroyapısal dönüşümler, kaynak metali ve ITAB (Isı Etkisi Altındaki Bölge) açısından incelenmiştir. Seyrelme miktarına bağlı olarak kaynak metali ve ITAB kimyasal içerik farklılığı SEM/EDS (Taramalı elektron Mikroskobu/Enerji Dağılımlı Spektrometre) yardımı haritalama işlemi ile saptanmıştır. Elde edilen kaynak metali düşük sıcaklıklarda yüksek tokluk özelliklerine sahiptir. Kaynak metali kimyasal içeriği seyrelme nedeniyle elementel değişimlere maruz kalmıştır.

Anahtar Kelimeler: Inconel 625, AISI 304L paslanmaz çelik, Mikroyapı, Sertlik, Tokluk

\section{Joining of Inconel 625 and AISI 304L Dissimilar Material Pairs using High-Nickel Content Filler Metal: Microstructural and Mechanical Properties}

\begin{abstract}
In this study, a couple of Inconel 625 nickel based super alloy and AISI 304 L austenitic stainless steel dissimilar materials were welded by TIG (gas tungsten arc welding) method using ErNiCr3 filler metal. A couple of dissimilar materials with different physical and chemical properties are joined with a high nickel content filler metal, and the weld metal microstructure, hardness and toughness properties of the weld are investigated. Microstructural transformations and intermetallic phases in the weld metal and at the melting boundary and precipitates formed in the structure have been characterized. Microstructural changes, which depend on the chemical composition of base metal are examined both in terms of weld metal and HAZ (Heat Affected Zone). Depending on the dilution amount, the difference in weld metal and HAZ chemical concentration was determined by SEM / EDS (Scanning Electron Microscopy/Energy Dispersive Spectroscopy) assistance mapping process. The obtained weld metal has high toughness properties at low temperatures. The chemical content of weld metal has exposed to partial elemental changes due to dilution.
\end{abstract}

Keywords: Inconel 625, AISI 304L stainless steel, Microstructure, Hardness, Toughness

*Sorumlu yazar (Corresponding author): Mustafa TÜMER, mustafa.tumer@kocaeli.edu.tr 


\section{GIiRIŞ}

Son y1llarda farklı cins malzemelerin birleştirilmesi endüstriyel olarak artan bir şekilde önem kazanmaktadır [1]. Çünkü bu sayede malzemeleri maliyetlerinin düşürülmesi ve geliştirilmesi tasarım esnekliği içerisinde sağlanmaktadır [2]. Nikel esaslı süper alaşımlar ve paslanmaz çelikler, buhar jeneratörleri, yakıt dönüştürücü ve petrol rafinerisinde piroliz tüpleri gibi yüksek sıcaklık ortamlarında yaygın olarak kullanılmaktadır [3]. Bu farklı cins malzeme çiftinin birleștirilebilmesi, sadece hizmet koşullarını yerine getirmesi değil, aynı zamanda kullanılan pahalı malzeme hacmini minimize ederek büyük tasarruflar ile sonuçlanmasını sağlar [4]. Katı çözelti ile güçlendirilmiş Inconel 625, bir Ni-Cr-Mo-Nb alaşımı olarak [5], yüksek korozyon direnci ve yüksek sıcaklık mukavemeti nedeniyle petrokimya, denizcilik endüstrileri ve nükleer santrallerde de çeşitlendirilmiş uygulamalara sahiptir [6]. Benzer şekilde ostenitik paslanmaz çelikler kimyasal ve petrokimya endüstrileri ile güç mühendisliği alanlarında mukavemet ve korozyon direncinin kombine özelliklerinden dolayı geniş bir uygulama yelpazesine sahiptir [4], [7]. Özellikle, paslanmaz çelik ile Ni esaslı süper alaşımlar arasındaki farklı cins malzeme birleştirmeleri, yüksek sıcaklık uygulamalarından orta derecede sıcaklık ortamlarına geçişte önemli avantajlara sahiptir [8]. Isıl genleşme katsayısı fark1, yüksek sıcaklıklarda uzun süre maruz kalma sonucu farklı cins malzeme birleştirmesinin 1s tesiri altındaki bölgesinde (ITAB) yorulma ve sürünme hatalarına neden olabilir. $\mathrm{Bu}$ birleştirmelerde $\mathrm{Ni}$ esaslı kaynak ilave metalinin kullanılması, yüksek sıcaklıklarda ısıl genleşme farklılıklarından kaynaklanan gerilmeleri daha iyi dağıtan kaynak eki meydana getirir. Ayrıca bu benzersiz kombinasyon için $\mathrm{Ni}$ bazlı ilave metalinin kullanılması metalürjik avantajlar da sağlamaktadır [9].

\section{2. ÖNCEKİ ÇALIŞMALAR}

Ramkumar ve arkadaşları [10] elektron 1şın kaynağı ile birleştirilmiş $\mathrm{Ni}$ esaslı süper alaşım
Inconel 625 ve UNS S32205 dubleks paslanmaz çelik plakaların metalürjik ve mekanik özelliklerini incelemiştir. İlgili çalışmada, farklı cins metalleri birleştirmek için ayrıntılı yapı-özellik ilişkileri sağlayarak, EB (Electron Beam) kaynağının bu malzemelerin birleştirmesinde kullanılabileceğini önermiştir. Naffakh ve arkadaşları AISI 310 ostenitik paslanmaz çelik ve Inconel 657 süper alaşım arasında gerçekleştirilen farklı cins metal birleştirmesini farklı kompozisyonlardaki ilave metallerle gerçekleştirmiş ve mikroyapısal olarak $\mathrm{NbC}$ çökelmelerini karakterize etmiştir [11]. Kumar ve arkadaşları, TIG kaynak yöntemi ile AISI 316L ve Inconel 625 malzeme çiftini ER2209 ve ERNiCr3 ilave metali ile çok pasolu olarak birleştirerek elde edilen kaynak bölgesi ve ITAB'ın karakterizasyonunu gerçekleştirmiştir. Mekanik ve metalürjik açıdan yapılan incelemelerde darbeli ark (PCTIG) ile elde edilen kaynak dikişlerinin darbe modu kullanılmadan (CCTIG) elde edilen kaynak metaline göre daha iyi bir performans ortaya gösterdiğini rapor edilmiştir [4].

Özellikle nikel bazlı alaşımların paslanmaz çelikler ile kaynaklanabilirliği konusunda, malzemenin temin özellikleri ve maliyeti nedeni ile sinırlı bilimsel çalışma bulunmaktadır. Bu sebeple bu çalışmada Inconel 625 nikel esaslı süper alaşım ile AISI 304L ostenitik paslanmaz çelik farklı cins malzeme çifti, TIG (gas tungsten arc welding) yöntemi ile ERNiCr3 ilave metali kullanılarak birleştirilebilirliği incelenmiştir.

\section{MATERYAL VE METOT}

Birleştirme işleminde TIG kaynak yöntemi kullanılmıştır. $\quad 350 \times 150 \mathrm{~mm}^{2}$ boyutlarında kullanılan plakaların kalınlığı AISI 304L için $8 \mathrm{~mm}$, Inconel 625 için ise $10 \mathrm{~mm}$ 'dir. $30^{\circ}$ tek taraflı kaynak ağzı açılmış ve $3 \mathrm{~mm}$ kök aralığı bırakılmıştır. Çok pasolu olarak gerçekleştirilen bu birleştirmede (7 paso) 95 amper akım ve 15 volt gerilim değeri ile kaynak hızlarına bağlı olarak, $1,73-2,51 \quad \mathrm{~kJ} / \mathrm{mm}$ aralığında $1 \mathrm{~s} 1$ girdisi hesaplanmıştır. AISI 304L ve Inconel 625 malzemelerin kimyasal kompozisyonları 
Çizelge 1'de verilmiştir. Birleştirme esnasında ve kaynak kök bölgesinde koruyucu gaz olarak Argon gazı kullanılmıştır. İlave metal olarak 2,4 mm çapında, kimyasal kompozisyonu Çizelge 1'de verilen ERNiCr3 ilave metali kullanılmıştır.

Çizelge 1. ERNiCr3 ilave metali

\begin{tabular}{|c|c|c|}
\hline \multirow{2}{*}{} & $\mathbf{N i}$ & 72,5 \\
\cline { 2 - 3 } & $\mathbf{C r}$ & 20 \\
\cline { 2 - 3 } & $\mathbf{M n}$ & 3 \\
\cline { 2 - 3 } & $\mathbf{S i}$ & 0,1 \\
\hline & $\mathbf{T i}$ & 0,4 \\
\hline & $\mathbf{C r}$ & 0,03 \\
\hline & $\mathbf{F e}$ & 1 \\
\hline
\end{tabular}

Çentik darbe deneyleri $20,-20$ ve $\quad-60 \quad{ }^{\circ} \mathrm{C}$ sıcaklıklarında gerçekleştirilmiştir. Her bir sıcaklık değeri için üç numene kesilmiş ve daha sonra $7,5 \times 10 \times 55 \mathrm{~mm}^{3}$ boyutunda mekanik işleme metodları ile hazırlanmıştır. Charpy V çentik darbe test numunesi, TS EN ISO 9016 uyarınca kaynak metaline uygulanmış, TS EN ISO 148-1'e göre test edilmiştir.

Kaynaklı plakalardan elde edilen numuneler mikroyapı incelemeleri için zımparalama ve parlatma işlemine tabi tutulmuş, $3: 1$ oranında $\mathrm{HCl}$ ve $\mathrm{NOH}_{3}$ çözeltisinde 10,4 V'ta 15 sn tutularak elektrolitik olarak dağlanmıştır.

Kaynak metalinin mikroyapısı ve çentik darbe deneyi sonucu oluşan kırılma yüzey morfolojileri JEOL JSM-6060LV marka Tarama Elektron Mikroskobu (SEM) ile yapılmıştır. Birleştirilen kaynaklı levhanın enine kesitinden çıkarılan numunelerin kaynak metaline Foundry Master Pro marka Optik Emisyon Spektrometre ile \% ağırlık olarak elementel analiz işlemi gerçekleştirilmiştir.

Metalografik inceleme için hazırlanan numuneler üzerinden sertlik ölçümleri alınmıştır. Mikrosertlik işlemi EmcoDuravision 250 marka cihaz ile görüntü kontrollü, $1 \mathrm{kgf}\left(\mathrm{HV}_{1}\right)$ yük uygulanarak gerçekleştirilmiştir. Ana malzeme, ITAB ve
Kaynak metalini takip eden bir çizgi boyunca 30 sertlik ölçümü kaynak metalinin kep, orta ve kök pasolarını kapsayacak şekilde alınmıştır.

Çizelge 2. Ana malzemeler

\begin{tabular}{|c|c|c|}
\hline Elementler & Inconel 625 & AISI304L \\
\hline $\mathbf{N i}$ & 61,1 & 8,01 \\
\hline $\mathbf{C r}$ & 21,7 & 18,6 \\
\hline $\mathbf{C}$ & 0,024 & 0,02 \\
\hline $\mathbf{M n}$ & 0,05 & 1,43 \\
\hline $\mathbf{S i}$ & 0,11 & 0,41 \\
\hline $\mathbf{M o}$ & 8,6 & 0,26 \\
\hline $\mathbf{N b}$ & 3,4 & - \\
\hline $\mathbf{F e}$ & 4,6 & Kalan \\
\hline
\end{tabular}

\section{DENEY SONUÇLARI VE TARTIŞMA}

ErNiCr3 ilave metali ile birleştirilen AISI 304L ve Inconel 625 malzemelerin kaynak metalini makro yapıs1 Şekil 1'de gösterilmiştir. Kesitsel makroyapının alındığı bölgede, çatlak, yetersiz ergime, yanma oluğu vb. gibi hatalar tespit edilmemiştir. Proses parametrelerinin de uygun olduğu görülmektedir. Ayrıca yapılan radyografik muayene sonucu kaynak metalinin tümünde yüzey altı inklüzyon, gözenek gibi hatalar tespit edilmemiştir.

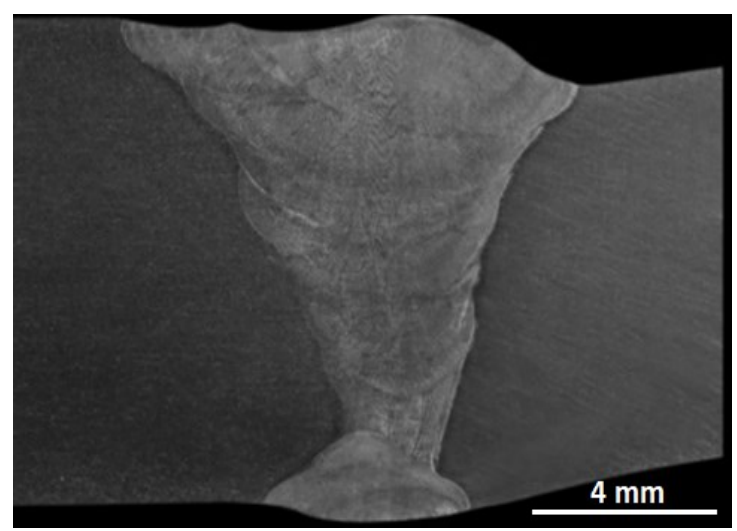

Şekil 1. Makroyap1 
Ergime esnasında seyrelme miktarına bağlı olarak farklı kimyasal kompozisyonlara sahip malzeme çifti ve ilave metalin kimyasal içeriğinin birleştirmenin kaynak metali bileşimine yapacağ 1 etki göz önünde bulundurularak, kaynak metalinin kesit yüzeyinden kimyasal analiz gerçekleştirilmiştir. Analiz sonuçları Çizelge 3'de verilmiştir. Fe elementi AISI 304L malzemenin içerisinde yaklaşık \%70 civarında bulunmasına rağmen, kaynak metali içerisine bu değer \%7,97 olarak tespit edilmiştir. Bu durum TIG kaynak yönteminin sağladığı düşük 1S1 girdisi sonucu seyrelmenin az olması nedeni ile gerçekleşmiştir. İlave metal içerisinde yaklaşık \%1 içeriğe sahip Fe elementi birleştirme esnasında AISI 304L tarafindan ergiyerek kaynak metaline karışması, bu elementin kaynak metali içerisindeki yüzdelik diliminin artmasina neden olmuştur. Nikel oranında yaklaşık \%9'luk bir azalma mevcuttur. $\mathrm{Cr}$ oranında kayda değer bir değişim meydana gelmemiştir. Sertlik ve yüksek sıcaklık çalışma dayanımı arttırıcı bir element olarak Mo ilave metalin içerisinde olmamasına rağmen kaynak metali içerisinde \%1,46 değerindedir. ERNiCr-3 ilave metali ile birleștirilen Inconel 625/AISI304L malzeme çiftinin kaynak metali kimyasal kompozisyon açısından belirgin bir oransal değişime sahiptir.

Çizelge 3. Kaynak metali kimyasal bileşim analizi

\begin{tabular}{|c|c|c|c|c|c|c|}
\hline $\mathbf{N i}$ & $\mathbf{C r}$ & $\mathbf{M o}$ & $\mathbf{N b}$ & $\mathbf{F e}$ & $\mathbf{M n}$ & $\mathbf{T i}$ \\
\hline 63,7 & 21,1 & 1,46 & 2,69 & 7,97 & 2,35 & 0,26 \\
\hline
\end{tabular}

Kaynak ilave metalinden yararlanılarak elde edilen farklı cins metal birleştirmesinin kaynak metali ve ITAB bölgesine ait mikroyapılar Şekil 2a-c'de gösterilmiştir. Kaynak metali mikroyapısında iki farklı tip dentirik yapı gözlemlenmiștir. Lineer ve birbirlerine paralel olarak oluşan sürekli kolonsal dendritik yapıların yanlarında aynı yöne sahip süreksiz kolonsal dendritler mevcuttur. ITAB incelendiğinde Inconel 625 ergime sınırına yakın bölgelerde ostenit tanelerinin büyüdüğü tespit edilmiştir.


Şekil 2. Mikroyap1 görüntüleri, a) ERNiCr3 Kaynak metali, b) Inconel 625 - ITAB, c) AISI 304L - ITAB 
AISI 304L ostenitik paslanamaz çelik malzemede ise ITAB'da tane büyümesi gerçekleşmemiştir. Fakat malzeme içinde paralel olarak hadde yönü boyunca uzanan $\delta$-ferrit şeritleri, düzensizleşerek ergime sınırı yanında form değişimine uğramıştır. Ergime sınırı çizgisi sonrası epitaksiyel taneler şeklinde büyüme gösteren kaynak metali mikroyapıs1 mevcuttur. Inconel 625 malzeme tarafındaki ergime sınırında ise ErNiCr-3 ilave metali ile oluşan kaynak metaline karışmaya çalışan ana malzeme kimyasal içeriğindeki elementler kısmen ergimiş bölgenin oluşumuna neden olmuştur (Şekil 2b). Bu durumu Inconel 625 tarafındaki ITAB'da çok daha belirgindir.

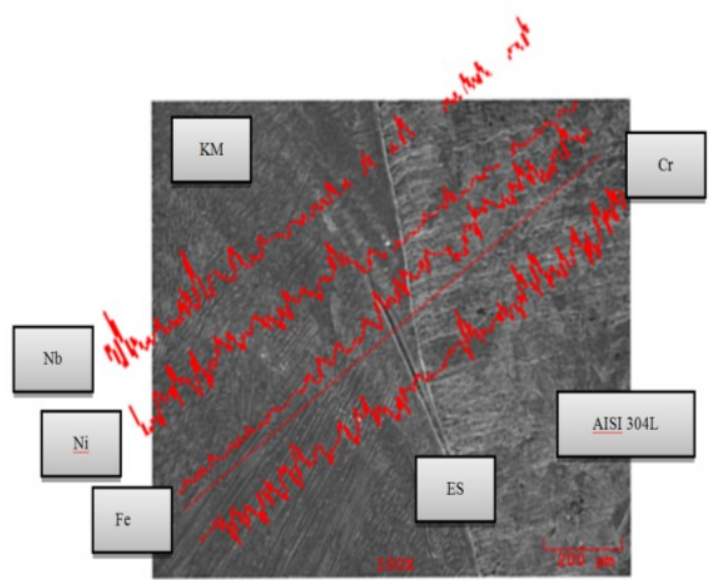

Şekil 3. ITAB’nin lineer EDS analizi

Ana malzemeler ve ilave metal açısından kimyasal kompozisyonda var olan farkın ergime sınırı alanındaki element geçişlerini incelemek için AISI 304L ITAB bölgesinde alınan SEM lineer element analizi Şekil 3'de gösterilmiştir. $\mathrm{Nb}$ ve $\mathrm{Ni}$ elementleri AISI 304L ana malzeme bölgesinden ERNiCr3 ilave metali ile elde edilen kaynak metaline doğru çizgi boyunca ilerledikçe artış gösterirken, $\mathrm{Cr}$ elementi hem ana malzemelerde hem de ilave metalde yaklaşık olarak aynı miktarda bulunmaktadır. Fe element oranı yüksek olan AISI 304L ostenitik paslanmaz çelik ana malzemeden $(\mathrm{Fe} \approx \% 70)$ kaynak metaline $(\mathrm{Fe} \approx \% 8)$ yaklaşık $25 \mu \mathrm{m}$ 'lik uzunlukta bir $\mathrm{Fe}$ elementi geçişi söz konusudur. Bu noktadan itibaren $\mathrm{Fe}$ elementinin miktarı ciddi şekilde düşüş göstermektedir.

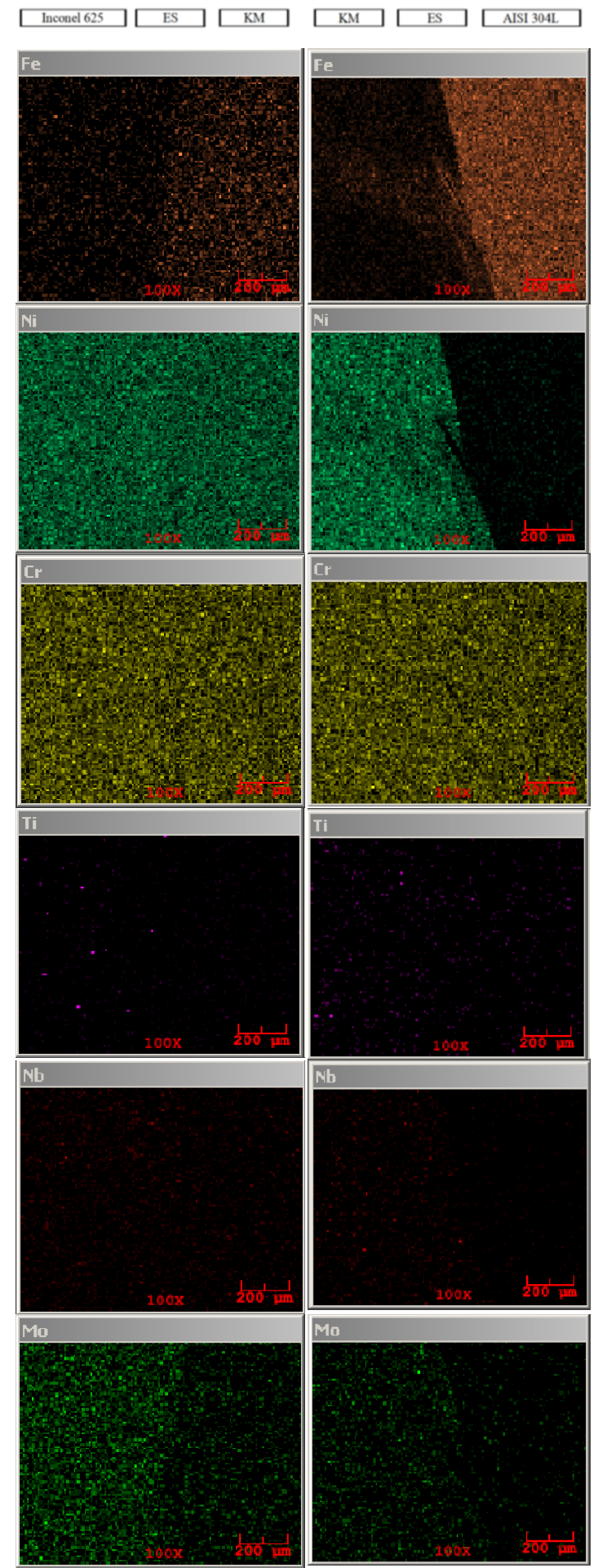

Şekil 4. ITAB'in elementel haritalanması 
Mikroyapıda aktif önem arz eden $\mathrm{Fe}, \mathrm{Ni}, \mathrm{Mo}, \mathrm{Cr}$ ve $\mathrm{Nb}$ gibi elementlerin ITAB'dan alınan EDS elementel haritalama sonuçları Şekil 4'de gösterilmiştir. Inconel 625 malzeme ve ErNiCr-3 kaynak metalinin kimyasal içeriği hemen hemen birbiri ile eşleşmektedir. $\mathrm{Bu}$ nedenle Inconel 625 ergime sınırı alanında element geçişlerinde çok büyük fark beklentisi bu nedenle olmamaktadır. AISI 304L ergime sınırında ise $\mathrm{Fe}$ elementi belirli bölgelerde kaynak metaline doğru bölgesel geçişler göstermektedir. Fakat Ni, Mo ve $\mathrm{Nb}$ elementlerinde ise ergime sınırı sonrasında kaynak metali kimyasal içeriğine bağl keskin bir artış söz konusudur. Diğer elementlerde ise (Cr ve Ti) belirgin bir element geçişi tespit edilememiştir.

Kaynak metalinin homojen olmayan mikroyapısından dolayı, kaynak metali içerisinde bazı çökelti oluşumları tespit edilmiştir. Beyaz renkli değişken formlu bu çökeltilere ait SEM görüntüsü ve EDS analizi Şekil 5'te gösterilmiştir. Küçük ve ince parçacıklar, dendrit içerisine yerleşmiş bir şekilde dağılım göstermektedir. Nikel alaşımı malzemelerde $\mathrm{Nb}$ kuvvetli bir stabilizasyon elementi olarak $\mathrm{NbC} /$ Laves fazı içeren nispeten düşük ergime noktalı nihai katılaşma ürünleri oluşturma eğilimi gösterir [5,12-14]. Beyaz interdentirik fazlar bu dönüşümün sonucudur. Inconel 625 ağırlıkça \% 3 niyobyum ve az miktarda karbon içerir. Bu nedenle ötektik yapının oluşumu kaçınılmazdır [11]. Şekil 5 b'de bulunan beyaz renkli çökeltiye yapılan EDS analizinde sırası ile ağırlık olarak $\% 33 \mathrm{Nb}$ ve \%39 Ti içermektedir. $\mathrm{Bu}$ durum çökeltinin intermetalik bir faz olduğunu kantlamaktadır. NbC, TiN, TiC ve Laves fazları gibi topolojik sıkı paket kafes yapısına sahip intermetalik fazlar nikel alaşımlı kaynak metalinde birçok çalı̧̧mada rapor edilmiştir [2,11,15-18]. Fakat bunların her biri elementel içeriğe bağlı olarak farklı formlarda ve kompozisyonda oluşumlar sergilemektedir. Örneğin Laves fazı hekzogonal kristal kafes yapısına sahiptir ve $\mathrm{A}_{2} \mathrm{~B}$ stokiometrisine sahip bir metalik bileşiktir, burada "A", $\mathrm{Ni}, \mathrm{Fe}, \mathrm{Cr}$ ve Co gibi elementleri temsil eder ve "B", $\mathrm{Nb}, \mathrm{Ti}, \mathrm{Si}$ ve Mo gibi elementleri temsil eder [18].
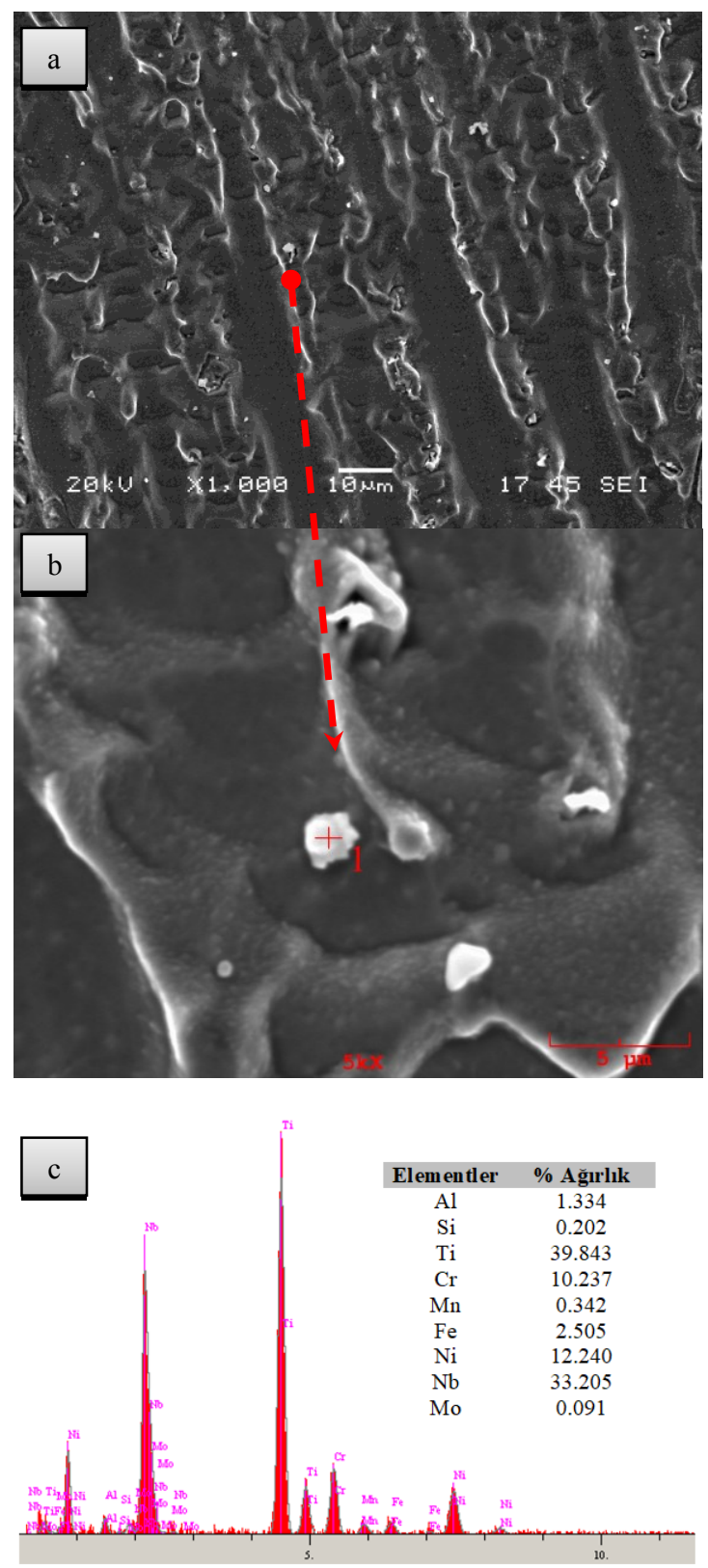

Şekil 5. SEM noktasal EDS analizi

Şekil 5a ve 5b incelendiğinde bu ötektik oluşumların kaynak metali içerisinde hemen hemen her bölgede bulunduğu görülmektedir. Kaynak metali ana matrisinde $\mathrm{Nb}$ elementindeki artış miktarına bağlı olarak, katılaşma işleminin son aşamasında bu elementin intermetalik faz 
oluşumuna neden olduğu daha önceki çalışmalarda rapor edilmiştir [19,20].

YMK (Yüzey Merkezli Kübik) kristal kafes yapısına sahip olan ostenit fazı kroyojenik sıcaklıklarda da iyi tokluk davranışı sergilemektedir. Inconel 625 - AISI 304L malzeme çiftinin ERNiCr3 ilave metali ile birleştirilmesi sonucu elde edilen kaynak metalinin çentik darbe dayanımına etkisini incelemek amacı ile numuneler $+20,-20,-60{ }^{\circ} \mathrm{C}$ sicaklıklarında çentik darbe testleri uygulanmıştır. Çentik darbe enerjisi değerleri Çizelge 4'de verilmiş, grafiksel olarak Şekil 6'da gösterilmiştir. Kullanılan ilave metalin yapısındaki $\mathrm{Cr}$ ve Mo içeriği ve oluşan sertlik değeri yüksek ikincil fazlara rağmen, ostenitik yapıya sahip kaynak metali belirtilen sıcaklıklarda sirasi ile 119,126 ve 123 joule (J) ortalama darbe tokluk enerjisine sahiptir. YMK kristal kafes yapısına sahip olan ostenit fazı kroyojenik sicaklıklarda da iyi tokluk davranışı sergilemekte ve sünek gevrek geçiş sicaklığı göstermemektedir. Darbe testi sonucu oluşan kırılma bölgelerinden alınan SEM görüntüleri Şekil 7'de gösterilmiştir. $\mathrm{Bu}$ bölgeler çukur ağ ana matrisi oluştururken, bütün test sicaklıklarda hemen hemen aynı formu destekleyen bir kırılma yüzeyi mevcuttur.

Çizelge 4. Charpy-V darbe testi sonuçları (J)

\begin{tabular}{|c|c|c|c|}
\hline Sicaklik $\left({ }^{\circ} \mathrm{C}\right)$ & 1. & 2. & 3. \\
\hline+20 & 130 & 113 & 115 \\
\hline-20 & 132 & 116 & 129 \\
\hline-60 & 122 & 119 & 130 \\
\hline
\end{tabular}

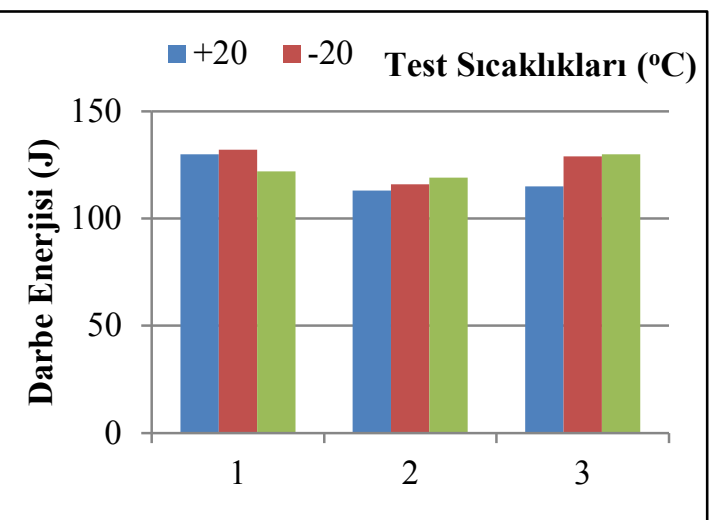

Şekil 7. Çentik darbe testi sonuçları grafiği
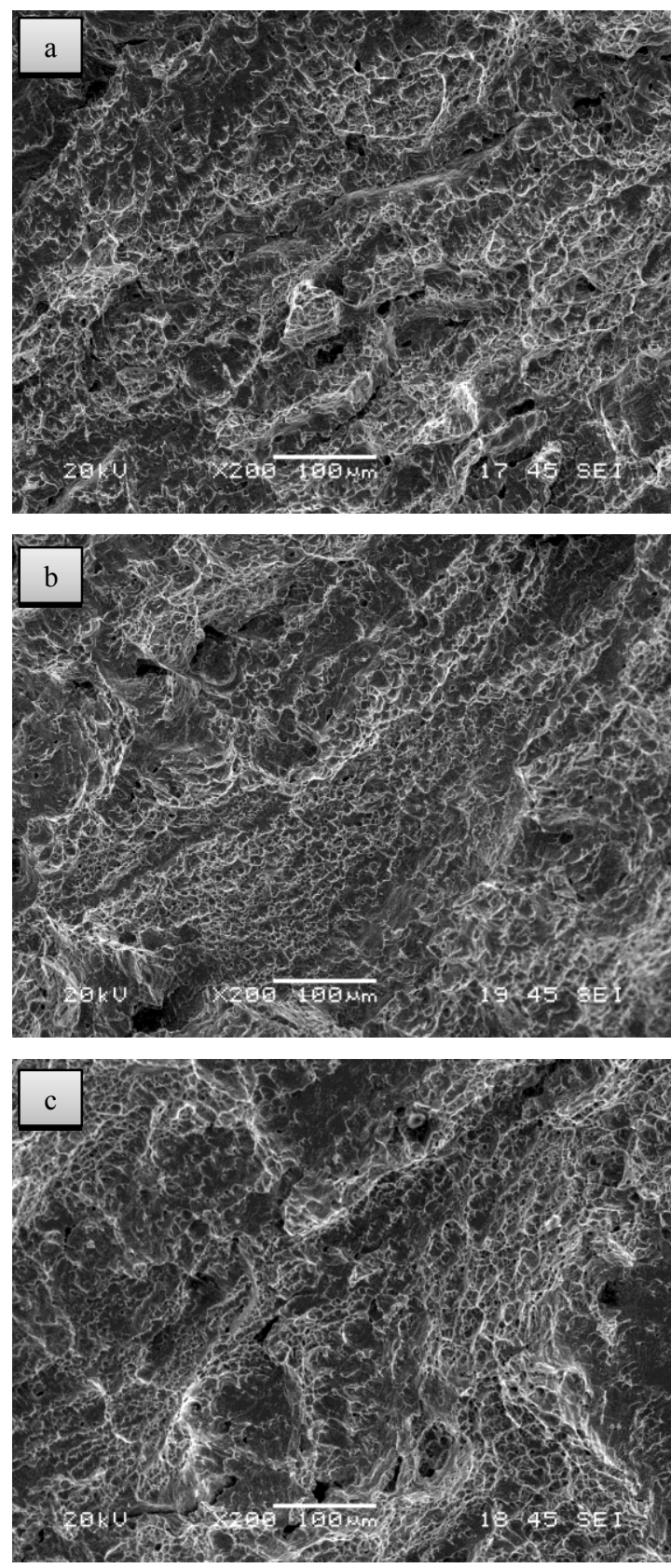

Şekil 7. Çentik darbe testi sonrası kırılma yüzeyleri a) $+20{ }^{\circ} \mathrm{C}$, b) $-20{ }^{\circ} \mathrm{C}$, b) $-60{ }^{\circ} \mathrm{C}$

TIG yöntemi ile birleştirilen Inconel 625-AISI 316L malzeme çiftinin kaynak bölgesi kesitinden sıralı olarak alınan mikrosertlik ölçümleri grafiksel olarak Şekil 8'de gösterilmiştir. Kaynak metalindeki sertlik 182-292 $\mathrm{HV}_{1}$, arasındadır. 
Kaynak metalinde kep bölgesinde sertlik değerleri diğer pasolara göre belirgin bir artış sergilemektedir. $\mathrm{Bu}$ durumun bu bölgeden hızlı soğumadan kaynaklı kolonsol dentrit yap1 oluşumundan kaynaklandığı düşünülmektedir. Birden fazla 1sıl etkiye maruz kalan kaynak metali orta ve kök bölgelerinde ise sertlik değerleri AISI 304L malzeme ile aynı bir çizgide ve 182-215 HV değerler aralığında sertlik değerleri ortaya koymaktadır. ITAB bölgesinde mikroyapısal açıdan ferritik çelikler gibi değişime uğramadıkları için sertlikleri ostenitik yapıya sahip ana malzemeler ile yaklaşık aynı değere sahiptir. Inconel 625 malzeme ortalama $240 \mathrm{HV}_{1}$, AISI $304 \mathrm{~L}$ malzeme ise $218 \mathrm{HV}_{1}$ ortalama sertlik değerine sahiptir.

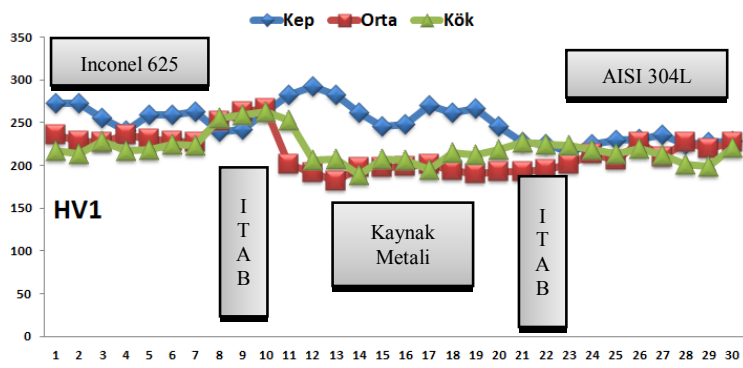

Şekil 8. Mikrosertlik değerleri

\section{SONUÇ}

Inconel 625 malzemelerin birleştirilmesinde genel olarak ERNiCrMo-3, AISI 304L ostenitik paslanmaz çelik malzemelerin birleştirilmesinde ise AISI 308L ilave metali kullanılmaktadır. Bu iki farklı cins malzemenin birleștirilmesinde eş birleştirme dışında önerilen bir ilave metal bulunmaması nedeni ile ERNiCr3 ilave metali ile birleştirilerek mekanik ve mikroyapısal özellikleri incelenmiştir. Elde edilen sonuçlar;

- Uygulanan çentik darbe testi sonucu elde edilen darbe enerjileri, birleştirmenin yeterli tokluğa sahip olduğunu ortaya koymaktadır. ERNiCr-3 Ni bazlı dolgu maddesi, kimyasal bileşimi ve mikroyapıyı modifiye ederek kaynaklı birleştirmenin sünekliğini önemli ölçüde artırmıştır.
- Mikroyapıda dentritler arasında dağılmış ve birbirinden kopuk daha çok küresel veya tanımsız şekiller formunda beyaz renkli, Ti ve $\mathrm{Nb}$ bakımından zengin intermetalik oluşumlar tespit edilmiştir.

- Kaynak metali mikroyapısında oluşan intermetalik fazların tokluk için belirgin bir etkiye sahip değildir.

- $\mathrm{Fe}, \mathrm{Ni}, \mathrm{Mo}$ ve $\mathrm{Nb}$ elementlerinin ana malzemelerden kaynak metaline seyrelme sonucu belirgin bir geçişi mevcuttur.

- Mikrosertlik değerleri, kaynak metalinin ergime sınırına yakın bölgelerinde ve ITAB'da ana malzeme ile aynı bir sertlik profili ortaya koymuştur.

\section{KAYNAKLAR}

1. Shah Hosseini, H., Shamanian, M., Kermanpur, A., 2011. Characterization of Microstructures and Mechanical Properties of Inconel 617/310 Stainless Steel Dissimilar Welds, Mater. Charact, 62(4), 425-431.

2. Mortezaie, A., Shamanian, M., 2014. An Assessment of Microstructure, Mechanical Properties and Corrosion Resistance of Dissimilar Welds Between, Inconel 718 and 310S Austenitic Stainless Steel, Int. J. Press. Vessel. Pip., 116(1), 37-46.

3. Sridhar, R., Devendranath Ramkumar, K., Arivazhagan, N., 2014. Characterization of Microstructure, Strength, and Toughness of Dissimilar Weldments of Inconel 625 and Duplex Stainless Steel SAF 2205, Acta Metall. Sin. (English Lett., 27(6), 1018-1030.

4. Kumar, K.G., Ramkumar, K.D., Arivazhagan, N., 2015. Characterization of Metallurgical and Mechanical Properties on the Multi-pass Welding of Inconel 625 and AISI 316L, J. Mech. Sci. Technol., 29(3), 1039-1047.

5. Li, G., Huang, J., Wu, Y., 2014. An Investigation on Microstructure and Properties of Dissimilar Welded Inconel 625 and SUS 304 using High-power $\mathrm{CO}_{2}$ laser, Int. J. Adv. Manuf. Technol., 76(5-8), 1203-1214.

6. Korrapati, P.K., Avasarala, V.K., Bhushan, M., Devendranath Ramkumar, K., Arivazhagan N., Narayanan, S., 2014. Assessment of 
Mechanical Properties of PCGTA Weldments of Inconel 625, Procedia Eng., 75, 9-13.

7. Y1lmaz, R., Tümer, M., 2013. Microstructural Studies and Impact Toughness of Dissimilar Weldments Between, AISI 316 L and AH36 steels by FCAW," Int. J. Adv. Manuf. Technol., 67(5-8), 1433-1447.

8. Kangazian, J., Shamanian, M., 2017. Mechanical and Microstructural Evaluation of SAF 2507 and Incoloy 825 Dissimilar Welds, J. Manuf. Process., 26, 407-418.

9. Sireesha, M., Albert, S.K., Shankar, V., Sundaresan, S., 2000. A Comparative Evaluation of Welding Consumables for Dissimilar Welds Between 310 Austenitic Stainless Steel and Inconel 657.pdf, 279, 65-76.

10. Devendranath Ramkumar, K., Sridhar, R., Periwal, S., Oza, S., Saxena, V., Hidad, P., Arivazhagan, N., 2015. Investigations on the Structure-Property Relationships of Electron Beam Welded Inconel 625 and UNS 32205, Mater. Des., 68, 158-166.

11. Naffakh, H., Shamanian, M., Ashrafizadeh, F., 2010. Microstructural Evolutions in Dissimilar Welds Between AISI 310 Austenitic Stainless Steel and Inconel 657, J. Mater. Sci., 45(10), 2564-2573.

12. Madhusudhana Reddy, G., Srinivasa Murthy, C.V., Srinivasa Rao, K., Prasad Rao, K., 2009. Improvement of Mechanical Properties of Inconel 718 Electron Beam Welds-influence of Welding Techniques and Postweld Heat Treatment, Int. J. Adv. Manuf. Technol., 43(7-8), 671-680.

13. Bae, S.H., Il Kwon, S., Yoon, J.G., Lee, J.H., Do, J.H., Kim, I.S., Choi, B.G., Jo, J.Y., Hong, H.U., 2014. Effect of Post Weld Heat Treatment on Cryogenic Mechanical Properties of Electron Beam Welded Cast Inconel 718, Metall. Mater. Trans. A Phys. Metall. Mater. Sci., 45(2), 537-542.

14. Ramkumar, K.D., Kumar, B.M., Krishnan, M.G., Dev, S., Bhalodi, A.J., Arivazhagan, N., Narayanan, S., 2015. Studies on the Weldability, Microstructure and Mechanical Properties of Activated Flux TIG Weldments of Inconel 718, Mater. Sci. Eng. A, 639, 234-244.
15. Naffakh, H., Shamanian, M., Ashrafizadeh, F., 2008. Influence of Artificial Aging on Microstructure and Mechanical Properties of Dissimilar Welds Between 310 Stainless Steel and INCONEL 657, Metall. Mater. Trans. A Phys. Metall. Mater. Sci., 39(10), 2403-2415.

16. Lippold, J.C., John, D.N., Kiser, S.D., 2009. Welding Metallurgy and Weldability of Nickel-Base Alloys. John Wiley \& Sons, Inc. All.

17. Naffakh, H., Shamanian, M., Ashrafizadeh, F., 2009. Dissimilar Welding of AISI 310 Austenitic Stainless Steel to Nickel-based Alloy Inconel 657, J. Mater. Process. Technol., 209(7), 3628-3639.

18. Xing, X., Di, X., Wang, B., 2014. The Effect of Post-weld Heat Treatment Temperature on the Microstructure of Inconel 625 Deposited Metal, J. Alloys Compd., 593, 110-116.

19. Kadoi, K., Shinozaki, K., 2017. Effect of Chemical Composition on Susceptibility to Weld Solidification Cracking in Austenitic Weld Metal, Metall. Mater. Trans. A Phys. Metall. Mater. Sci., 48(12), 5860-5869.

20. Wang, H., He, G., 2016. Effects of $\mathrm{Nb} / \mathrm{Cr}$ on the Cryogenic Impact Toughness of the Deposited Metal of ENiCrFe-9," Mater. Sci. Eng. A, 672, 15-22. 
